\title{
Chronic measurement, using a Doppler probe, of uterine artery flow in the gravid guinea-pig
}

\author{
C. P. Weiner, J. Herrig, J. Wang, L. Wang, D. Farley, D. Van Orden and \\ D. Chestnut
}

Department of Obstetrics and Gynecology, Division of Maternal-Fetal Medicine, University of Iowa Hospitals and Clinics, Iowa City, IA 52242, U.S.A.

\begin{abstract}
Summary. A chronic animal model is described which permits for the first time the continuous measurement of uterine artery blood flow velocity in the pregnant guineapig by using a miniaturized Doppler flow probe. Preliminary validation revealed that alterations in actual blood flow are directly and proportionally related to the change in the Doppler shift ( $r=0.984$ ) from 0 to $100 \mathrm{ml} / \mathrm{h}$. The velocity signal baseline was as stable as that of systemic blood pressure. Depending upon the individual animal's flow velocity, a deviation of $2-5 \%$ from baseline was statistically significant. With experience, $>90 \%$ of preparations were successful and a 30 -day interval was often available for study. Uterine artery flow velocity increased steadily between 45 and 55 days of gestation. Instrumentation did not result in fetal growth retardation. A reduction in flow velocity occurred during general anaesthesia using ketamine and the antianxietal xylazine. In agreement with the reports of other investigators using a different model, both hydralazine and angiotensin II increased uterine blood velocity and adrenaline reduced it.
\end{abstract}

\section{Introduction}

The guinea-pig has become increasingly popular over the past decade for the study of pregnancy. The advantages of these animals include economy, a haemomonochorial placenta (labyrinth type), cyclic changes in serum oestrogen and progesterone concentrations qualitatively similar to those observed in women, and cardiovascular/respiratory alterations during pregnancy analogous to those in women (Enders, 1965; Challis, Heap \& Illingworth, 1971; Martensson, Sjoquist, Bjellin \& Carter, 1979; Hosenpud, Hart, Morton, Hohimer \& Resko, 1983; Morton et al., 1984). However, the animal's small size has proved a disadvantage in studies requiring blood flow measurement. The diameter of the uterine artery $(0.5-1.0 \mathrm{~mm}$ at $\sim 52$ days of the 65 -day gestation) and its mobility within the mesometrium have made chronic continuous measurement of blood flow impossible. Even the smallest electromagnetic flow probe will twist and occlude uterine artery blood flow in the active animal. All previous investigations of uterine blood flow in the guinea-pig have therefore been based upon acute preparations using electromagnetic flow probes or chronic preparations using radiolabelled microspheres. The merits of continuous and microsphere blood flow measurements have been discussed in earlier publications (Woodcock, 1975). Rather than being mutually exclusive, the two techniques can complement each other, the former applicable to continuous measurements of flow in larger vessels and the latter to point measurements of flow in the microcirculation. There is currently no method which permits the chronic, continuous measurement of uterine blood flow in the guinea-pig.

We have applied Doppler technology for the continuous measurement of uterine artery flow velocity in the pregnant guinea-pig and placed a miniaturized Doppler flow probe directly upon the 
uterine artery in a chronic preparation. We present in this report a description, the success rate, and the initial validation of the model.

\section{Materials and Methods}

Probe construction. The construction of the Doppler probe has previously been described in detail (Van Orden, Farley, Fastenow \& Brody, 1984). A $20-\mathrm{MHz}$ piezoelectric crystal (1.5 mm in diameter; Valpey-Fisher, Hopkinton, MA), cut into quarter pie-shaped pieces so that the straight sides are $0.75 \mathrm{~mm}$, functions as both transmitter and receiver. The probe leads are constructed from two 40-cm segments of 36-gauge, 20-strand stainless-steel wire (Cooner, Chatsworth, CA). A 5-mm segment is cleaned of insulation, reduced to 4 strands and tinned with $60 / 40 \mathrm{tin} / \mathrm{lead}(\mathrm{w} / \mathrm{w})$ solder to minimize the solder necessary to join the wire to the crystal face. One lead is soldered to each side of the crystal at the apex of the pie-shaped crystal wedge (Fig. 1). It is essential that, to prevent obstruction or deformation of the crystal face, the solder spread be limited to the diameter of the tinned wire.

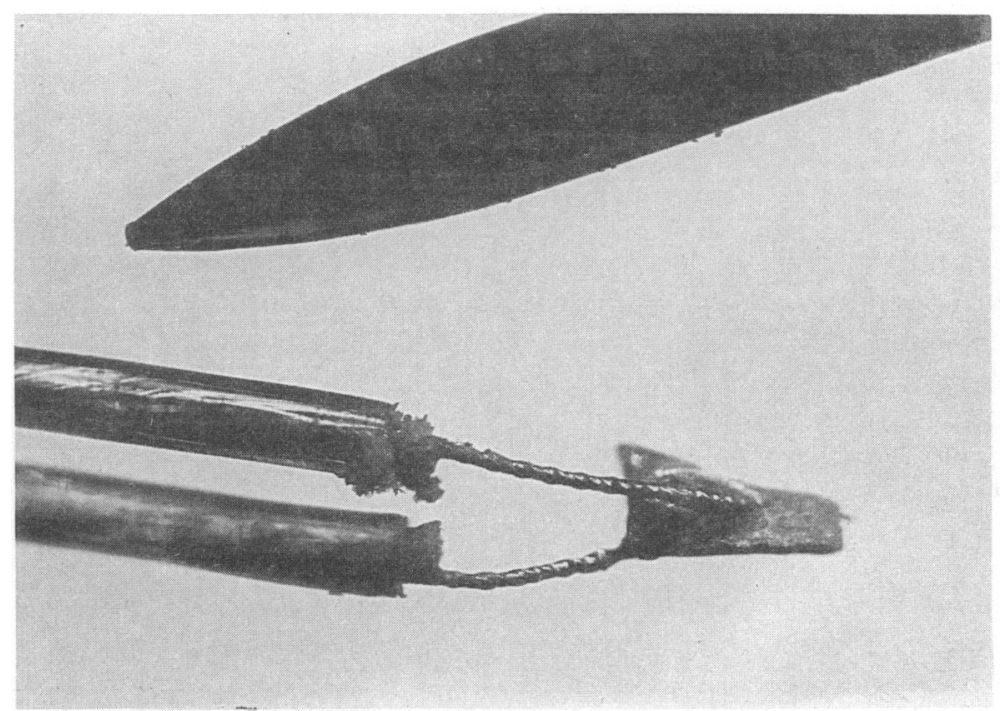

Fig. 1. A finished Doppler flow probe before implantation. A straight pin serves for comparison. $\times 8$.

Doppler flowmeter. The Doppler flowmeters used for these studies are a modification of a design by Craig Hartley, Baylor University (Hartley \& Cole, 1974). They have been modified by the Bioengineering Resource Facility at the University of Iowa for directional or nondirectional reception. The units are calibrated against a standard signal generator which is accurate to $2 \%$.

Animal preparation. Mixed breed guinea-pigs of known mating were obtained from a commercial breeder $\sim 40$ days of pregnancy (term 65 days) and allowed to acclimatize to the laboratory surroundings for 3-4 days. Guinea-pig chow (Purina) and water were supplied ad libitum along with fresh vegetables every few days.

After trial and error, the following anaesthetic regimen was used. The animal was premedicated with $0.8 \mathrm{mg}$ xylazine $/ \mathrm{kg}$, i.m. and general anaesthesia was induced $10 \mathrm{~min}$ later with an intraperitoneal injection of ketamine $(80 \mathrm{mg} / \mathrm{kg})$ mixed with acetylpromazine $(1: 30 \mathrm{v} / \mathrm{v})$. The operative sites were clean shaven, the surgical area was washed with iodoform, and the site draped in a 
sterile fashion. Oxygen (100\%) was administered by mask, but the animal was not mechanically ventilated. Body temperature was maintained with a small animal heating pad (Hamilton Aquamatic, $\mathrm{K} 20$, Cinncinati, $\mathrm{OH})$. Oxytetracycline $(30 \mathrm{mg} / \mathrm{kg}$ i.m. $)$ was administered preoperatively and on the third postoperative day to minimize infectious complications.

Catheters (polyethylene 50; i.d. $0.58 \mathrm{~mm}$, o.d. $0.965 \mathrm{~mm}$, Clay Adams, Parsippany, NJ) were inserted under aseptic conditions into the external jugular vein and the carotid artery was isolated through a ventral, midline neck incision. The carotid artery catheter was advanced a measured distance to a location within the descending aorta below the origin of the renal arteries. The arterial and venous catheters were secured to the vessel with silk sutures and then exteriorized through a stab wound in the nape of the neck. A constant infusion of isoproterenol $(16.7 \mu \mathrm{g} / \mathrm{kg} / \mathrm{min})$ (Elkins-Sinn, Inc., Cherry Hill, NJ) was initiated to minimize any anaesthetic-related decline in placental perfusion (Myers, Sparks, Makowski, Meschia \& Battaglia, 1982).

The abdomen was entered through a midline incision. Additional ketamine was given i.v. or i.a. to minimize intestinal protrusion. The number of young in each horn was determined by gentle palpation. A 5-10-mm segment of the uterine artery between two young was guided into the operative field and sharply isolated with the aid of an operating microscope (Nikon SMZ-10, Garden City, NY), using microsurgical instruments to minimize trauma. The exposed viscera outside the operative field were covered with gauze and frequently lavaged with warm, lactated Ringer's solution. A wedge of Parafilm was slid beneath the vessel to separate it from the underlying tissues and to support the probe. The surface of the artery was flooded with a solution of $1 \%$ xylocaine to achieve maximal vasodilatation. The Doppler probe was placed between the Parafilm and the artery, with the lead wires parallel to the mesometrium and directed towards the midline (Fig. 2). The angle between the artery and the probe at which maximal flow velocity was achieved was ascertained by manually adjusting the orientation of the probe while listening to the sound and observing the waveform and flow velocity recorded on a dynograph (Sensor Medics Corp., model No. R511A, Anaheim, CA). The probe was fixed to the underside of vascular adventitia with a small drop of cyanoacrylate glue (Krazy Glue, Ibasca, IL) applied from the tip of a fine wire. It is important that the glue be applied only to the crystal and the inferior portion of the artery, since encasement of the vessel by glue resulted in a permanent stricture. The sound transmission was not

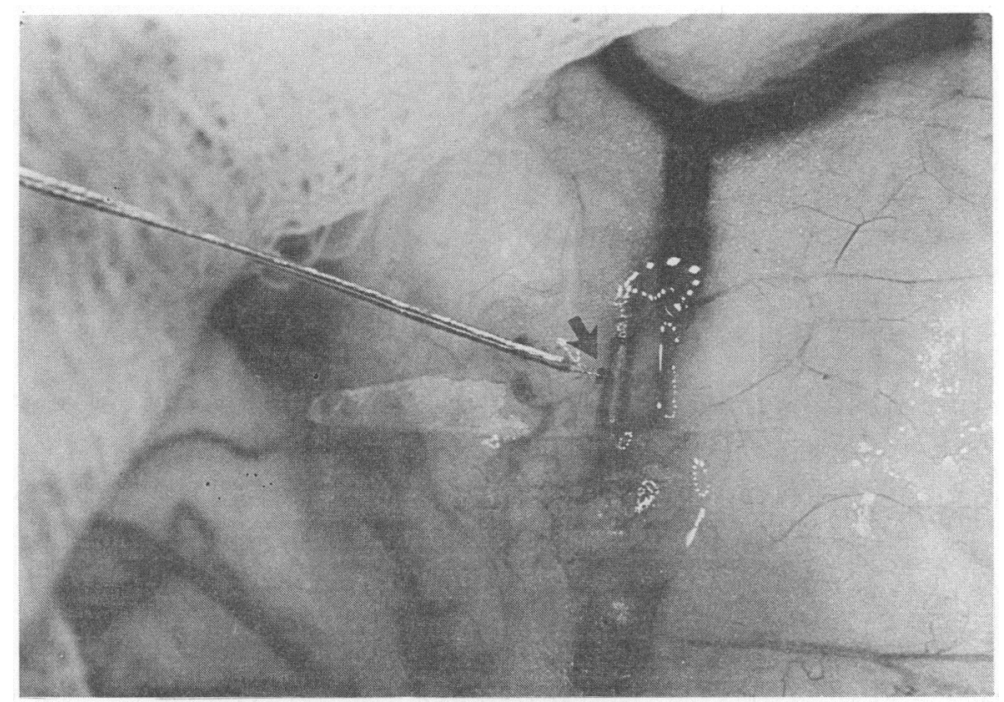

Fig. 2. An intraoperative view of a flow probe (arrow) after it has been glued into place. The uterine horn has been exteriorized for demonstration purposes. 
noticeably dampened by the glue. Xylocaine was reapplied after the glue had dried, and the vessel was observed until any spasm had resolved. The attached probe and exposed vessel were then covered with a small quantity of medical grade silicone polymer (Dow Corning, Midland, MI). After the polymer had hardened (2-3 min), the wire leads and the Parafilm platform were anchored in the mesometrium with 7-0 nylon sutures so that any shift in the position of the uterus, whether from fetal movement, uterine growth, or bowel, would flex the wire at the ligature and not the probe site. The leads were exteriorized through a puncture wound in the abdominal wall, anchored in the fascia with a 3-0 silk ligature, tunnelled subcutaneously to the nape of the neck, and brought out through the stab wound with the catheters. All skin incisions were closed with interrupted ligatures of resorbable suture. The oxygen and isoproterenol were continued until the animal became prone. At this time, an infusion of lactated Ringers solution with $5 \%$ dextrose was started at $10 \mathrm{ml} / \mathrm{h}$ and continued for $18 \mathrm{~h}$. The time to prepare the animal as described was $90-100 \mathrm{~min}$. Placement of additional flow probes and/or cannula is readily feasible. Animals assigned for chronic infusion studies were fitted with a nylon harness (Alice Martin, Chatsworth, CA) which permits free movement within the pen. No studies were begun until the animal had resumed normal activity and weight gain, and never before the 5 th post-operative day.

Measurements taken. Blood pressure and pulse were obtained through the descending aorta catheter (Electromedics transducer, model No. MS20-BA07ADS). The pressure was recorded as the mean arterial blood pressure (MAP).

Previous study (Haywood, Shaffer, Fastenow, Fink \& Brody, 1981) has demonstrated that if the criteria for linear proportionality of velocity and actual flow are met, the resistance of the vascular bed may be calculated as:

$$
\% \text { change in resistance }=[(\mathrm{Rt}-\mathrm{Rc}) / \mathrm{Rc}] \times 100 \%
$$

where resistance during the control interval $(\mathrm{Rc})=\mathrm{MAPc} / \mathrm{MVSc}$ and resistance during the test period $(\mathrm{Rt})=\mathrm{MAPt} / \mathrm{MVSt}$ and MVS represents the mean velocity signal. Resistance may therefore be estimated two ways: either by the MVS if linear proportionality is demonstrated with this model, or by calculating any one of a number of waveform analyses such as pulsatility index and systolic velocity:diastolic velocity ratio.

Correlation between absolute flow and the Doppler shift. The relationship between the Doppler shift and actual blood flow was examined by infusing blood at known rates upstream from the probe of a chronically instrumented uterine artery. By 1 month after probe implantation, a noisefree, pulsatile Doppler signal was documented. The animal was anaesthetized and the abdomen opened. The range setting of the probe was adjusted to achieve the maximum Doppler shift as blood flowed freely through the artery.

The equivalence of electrical zero for the Doppler flow probe and true zero flow through the vessel was examined by first interrupting the circuit to the probe (electrical zero) and recording that point. After reestablishing electrical current to the probe and demonstrating the pulsatile pattern, the vessel was manually occluded. The MVS corresponding to zero flow was recorded and compared to electrical zero. The uterine artery was then cannulated $5 \mathrm{~cm}$ above the probe with a polyethylene No. 10 catheter (o.d. $0.61 \mathrm{~mm}$, i.d. $0.28 \mathrm{~mm}$ ). At $4 \mathrm{~cm}$ below the probe, the vessel was occluded with a single ligature and the vessel severed on the probe side of the ligature to permit free egress of blood. The arteriolar branches in the involved segment were not ligated, thus duplicating as many of the chronic conditions as possible. The uterine artery catheter was attached to a Harvard pump (model No. 2716, Southnatwick, MA) and heparinized guinea-pig whole blood warmed to body temperature was continuously infused at rates from 10 to $100 \mathrm{ml} / \mathrm{h}$ until the signal at each infusion rate was steady. The mean $\mathrm{kHz}$ shift for each rate was plotted against the actual flow rate.

Alterations in flow velocity in response to vasoactive agents. Because equipment limitations prevented a more rapid infusion of blood, we sought to determine in 15 different animals the effect 
upon flow velocity of three vasoactive substances that have been used for investigations in the gravid ewe. The drugs were administered intravenously. Two vasopressors were selected because of their opposite effects upon uterine artery blood flow. Angiotensin II (Sigma Chemical Co., St Louis, MO) has been reported to increase uterine blood flow at low infusion rates and adrenaline (Elkins-Sinn, Inc., Cherry Hill, NJ) to reduce flow (Tabsh et al., 1981). Hydralazine (Ciba Pharmaceutical Co., Summit, NJ) was selected because it is reported to reduce systemic blood pressure and peripheral resistance while increasing uterine artery blood flow (Ring, Krames, Shnider, Wallis \& Levinson, 1977).

\section{Results}

\section{Correlation between absolute flow and the Doppler shift}

In all instances, true zero flow was identical to electrical zero. The mean $\mathrm{kHz}$ shift at each flow rate (11 rates, mean of 5.4 trials per rate) was directly proportional to the infusion rate (Fig. 3 ). The correlation coefficient between actual blood flow and the Doppler shift was $0.984\left(r^{2}=0.968\right)$. Changes in actual flow rate were directly proportional to changes in the $\mathrm{kHz}$ shift.

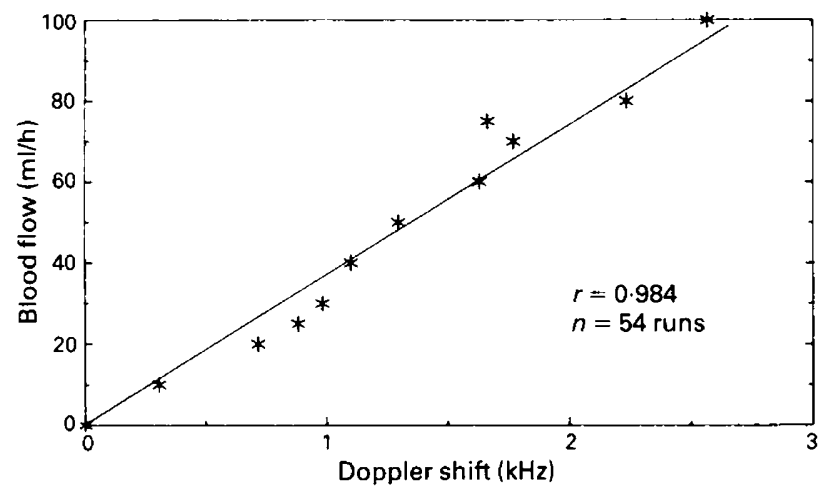

Fig. 3. The correlation between actual flow and the Doppler shift is high between 0 and $100 \mathrm{ml} / \mathrm{h}$ and the relationship is linear.

\section{Baseline stability}

Baseline stability is essential if the effect of experimental manipulation is to be accurately interpreted. Measurements of mean arterial blood pressure (MAP), mean velocity signal (MVS) and resistance $(R)$ were obtained at $1-\mathrm{min}$ intervals for $10 \mathrm{~min}$ ( 8 animals) and at 5 -min intervals for $60 \mathrm{~min}$ ( 11 animals). These measurements were then subjected to time plot analyses. A line of best fit for each animal was constructed and the slopes compared to zero. Not surprisingly, the slopes for MAP over the 10- and 60-min intervals were significantly different from zero. This reflects the known minute-to-minute homeostatic alterations in blood pressure which occur in the intact and unanaesthetized animal. Similar changes were seen in blood flow velocity. The magnitude of these trends was investigated by constructing a statistical model using analysis of covariance and calculating the 95th and 99th percentile prediction intervals (Table 1). The model is described by the equation.

$$
\mathrm{Y}=\mathrm{Bo}+\mathrm{B} 1 \mathrm{Time}+\mathrm{B} 2 \mathrm{ID}+\mathrm{B} 3 \mathrm{ID} * \text { Time }
$$

where Y represents either of the dependent variables (MVS, MAP, or R at time $x$ ), Bo the $y$ intercept, B1-B3 a description of the relationship between the respective independent parameter 
Table 1. Baseline stability over 10 - or 60 -min intervals

\begin{tabular}{llccc}
\hline Interval & Measure & Resistance & $\begin{array}{c}\text { Deviation of } 95 \% \\
\text { prediction interval }\end{array}$ & $\begin{array}{c}\text { Deviation of } 99 \% \\
\text { prediction interval }\end{array}$ \\
\hline \multirow{2}{*}{$10 \mathrm{~min}$} & $\mathrm{kHz}$ & 0.9959 & 0.215 & 0.285 \\
& MAP* & 0.9931 & 3.965 & 5.241 \\
& $\mathrm{R} \times$ time $^{\dagger}$ & 0.9945 & 0.719 & 0.951 \\
$60 \mathrm{~min}$ & & & & \\
& kHz & 0.9824 & 0.436 & 0.578 \\
& MAP* & 0.9799 & 6.895 & 9.123 \\
& R $\times$ time† & 0.9796 & 1.538 & 2.036 \\
\hline
\end{tabular}

* mmHg.

$\dagger$ Resistance at time $x$.

and $\mathrm{Y}$ when controlling for the other factors, and ID the individual animal. Models utilizing blood pressure or uterine blood flow velocity confirm a significant interaction effect between guinea-pig and time. The $r^{2}$ is large for each parameter, and so most of the variance is accounted for along the line of best fit. As would be expected, the predictive intervals are widest for the 60 -min intervals since an increasing number of trends are likely to occur with increasing duration. However, even over $60 \mathrm{~min}$, the Doppler shift baseline was remarkably stable and suggests that small deflections from baseline are potentially detectable. The uterine artery flow velocity was at least as stable as MAP.

\section{Alterations in flow velocity in response to vasoactive agents}

Hydralazine reduced MAP and uterine resistance while increasing the MVS in a direct doseresponse fashion, a $73 \%$ increase over baseline at $0.4 \mathrm{mg} / \mathrm{kg}$ (Table 2). Although angiotensin II and adrenaline significantly increased the MAP $(P<0.05)$, only adrenaline reduced the MVS. Angiotensin II significantly increased the MVS by 40-50\%, suggesting that, as in the ewe, these concentrations of angiotensin II increase uterine blood flow.

Table 2. Effect of vasoactive agents expressed as the percentage change in uterine artery flow velocity (MVS), blood pressure (MAP), and resistance (R) in the pregnant guinea-pig (mean \pm 1 s.d. for $\mathrm{N}$ animals)

\begin{tabular}{|c|c|c|c|c|c|c|c|}
\hline & \multicolumn{2}{|c|}{ Angiotensin II ( $\mathrm{ng} / \mathrm{min})$} & \multicolumn{3}{|c|}{ Hydralazine $(\mathrm{mg} / \mathrm{kg}$ ) } & \multicolumn{2}{|c|}{ Adrenaline (mg/kg) } \\
\hline & $\begin{array}{c}14 \cdot 5 \\
(N=6)\end{array}$ & $\left(\begin{array}{c}29 \\
\left(N^{=} 6\right)\end{array}\right.$ & $\begin{array}{c}0.08 \\
(\mathrm{~N}=5)\end{array}$ & $\begin{array}{c}0.2 \\
(\mathrm{~N}=6)\end{array}$ & $\begin{array}{c}0.4 \\
(\mathrm{~N}=6)\end{array}$ & $\begin{array}{c}0.0005 \\
(\mathbf{N}=3)\end{array}$ & $\begin{array}{c}0.001 \\
(\mathrm{~N}=3)\end{array}$ \\
\hline MAP & $\begin{array}{c}18 \cdot 6 \pm \\
8 \cdot 1\end{array}$ & $\begin{array}{c}42 \cdot 3 \pm \\
38.8\end{array}$ & $\begin{array}{c}-12.5 \pm \\
11.6\end{array}$ & $\begin{array}{c}-34.9 \pm \\
32.7\end{array}$ & $\begin{array}{c}-48 \cdot 1 \pm \\
17 \cdot 5\end{array}$ & $\begin{array}{c}22 \cdot 2 \pm \\
7 \cdot 1\end{array}$ & $\begin{array}{c}36 \cdot 6 \pm \\
14 \cdot 3\end{array}$ \\
\hline MVS & $\begin{array}{l}39 \cdot 3 \pm \\
31 \cdot 3\end{array}$ & $\begin{array}{c}55 \cdot 6 \pm \\
38.8\end{array}$ & $\begin{array}{l}19 \cdot 0 \pm \\
8.4\end{array}$ & $\begin{array}{l}39 \cdot 7 \pm \\
16 \cdot 6\end{array}$ & $\begin{array}{l}73.4 \pm \\
34.6\end{array}$ & $\begin{array}{c}-47 \cdot 5 \pm \\
16 \cdot 4\end{array}$ & $\begin{array}{c}-47.5 \pm \\
21.8\end{array}$ \\
\hline $\mathrm{R}$ & $\begin{array}{c}-5 \cdot 4 \pm \\
30 \cdot 35\end{array}$ & $\begin{array}{l}0.6 \pm \\
27.65\end{array}$ & $\begin{array}{c}-21.6 \pm \\
12.6\end{array}$ & $\begin{array}{c}-39.7 \pm \\
15.7\end{array}$ & $\begin{array}{c}-48 \cdot 1 \pm \\
17 \cdot 5\end{array}$ & $\begin{array}{l}149 \cdot 6 \pm \\
86\end{array}$ & $\begin{array}{c}387.6 \pm \\
274\end{array}$ \\
\hline
\end{tabular}

\section{Changes in flow velocity as gestation advances}

Baseline flow velocity was measured longitudinally at intervals between 45 and 65 days of gestation in 9 animals beginning at least 5 days after surgery (Fig. 4). The Doppler shift increased by a mean of $96 \pm 59 \%$ (s.d.; the magnitude of increase ranged from $38 \%$ to $185 \%$ ), despite the fact that the animals were being subjected to frequent experiments. The largest increases were seen 


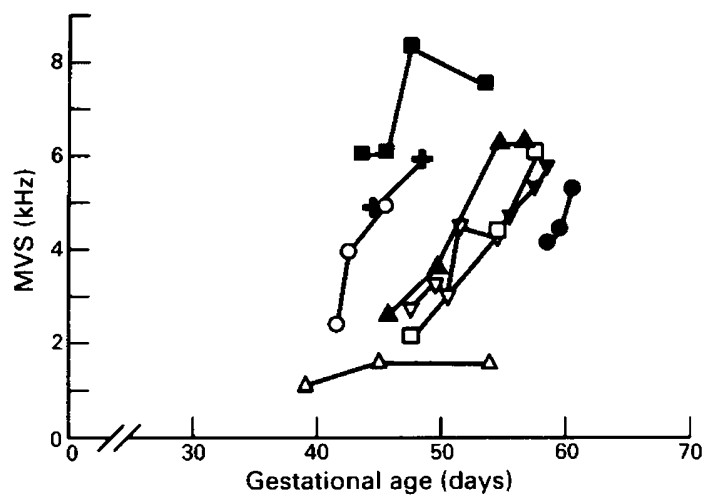

Fig. 4. Uterine artery blood flow velocity plotted against advancing gestational age in 9 different animals. The magnitude of change reflects the number of young present. The mean increase in flow velocity from 45 to 65 days was $96 \%$.

in animals with the largest litters and the smallest increase occurred in a pregnancy with only 1 young. Although not shown, occasional transient flow reversal and frequent erratic uterine artery flow velocity was noted between 58 and 65 days.

\section{Effect of anaesthesia}

Myers et al. (1982) reported a reduction in uteroplacental blood flow secondary to xylazine but not ketamine. Our studies support their observation of diminished flow with this anaesthetic combination. A sample tracing with calibration segments excised to enhance the continuity demonstrates an increase in the MVS as the animal recovers from general anaesthesia (Fig. 5). Although not shown, a 20-30\% reduction in the MAP was common when $>0.8 \mathrm{mg}$ xylazine $/ \mathrm{kg}$ was used.

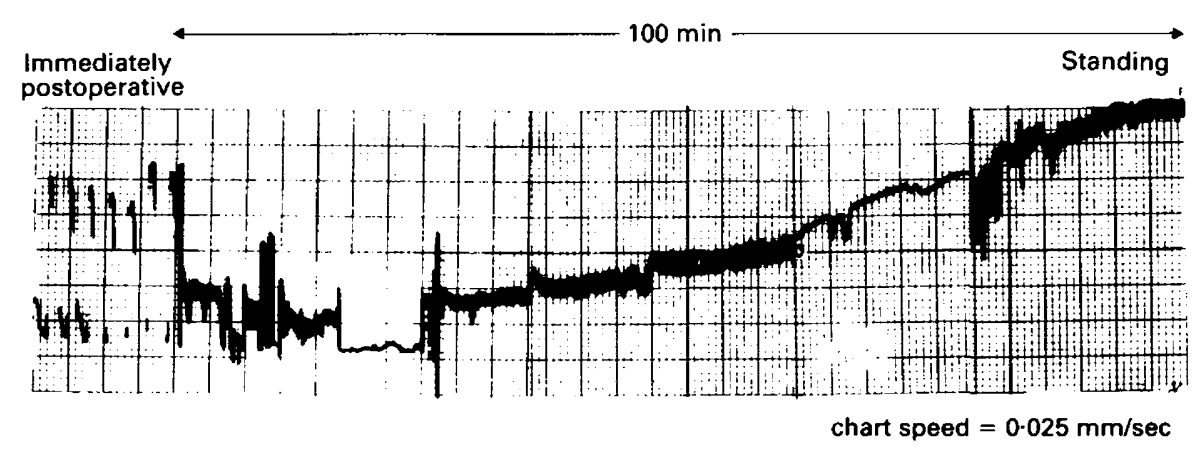

Fig. 5. Uterine artery flow velocity is dramatically reduced under general anaesthesia induced by ketamine and xylazine, despite a continuous infusion of isoproterenol to maintain heart rate.

\section{Pregnancy wastage}

A successful model was defined as continuation of a viable pregnancy with a working probe and patent cannula for at least 1 week after operation. Our success rate increased as surgical technique and anaesthesia improved, with 1, 3 and 11 successes for the first, second and third batches of 
20 animals, and 18/19 animals in the latest batch. The greatest number of failures overall was secondary to abortion, defined as delivery within 1 week of surgery $(70 \%)$. Probe failure occurred in $4 \%$ and catheter occlusion at some point before delivery occurred in about $10 \%$. However, with our recent high success rate, catheter occlusion has become the most common cause of failure. Premature delivery ( $>1$ week post-operatively but before 62 days) seemed related to the types of drugs studied (especially adrenaline) and to the frequency of experimentation.

The mean birthweight for viable young was $79 \cdot 7 \pm 21 \mathrm{~g}$ and the mean litter size was 3 (range 1-5). If only those animals that were instrumented but not subjected to drug treatment (because of catheter or probe failure) were considered, the mean birthweight was $103.1 \pm 9.8 \mathrm{~g}$ (mean litter size $=2$ ). No animal in this group delivered prematurely. The means of both groups are similar to published norms when adjusted for the number of pups in the litter and gestational age at delivery (Draper, 1920). The stillbirth rate for pregnancies ending with at least one viable young was $42 \%$. However, stillbirths were observed predominantly in animals receiving study drugs and were most common in pregnancies ending before 62 days of gestation. The mean birthweight of stillborn young was $57 \cdot 4 \pm 24 \cdot 6 \mathrm{~g}$.

\section{Discussion}

The mean velocity signal correlates highly with actual flow and therefore may be used to calculate changes of resistance in the vascular bed downstream from the flow probe. Our findings confirm previous studies involving arterial blood flow in the nonpregnant rabbit and the rat (Haywood, Shaffer, Fastenow, Fink \& Brody, 1981; Van Orden et al., 1984). Although it is tempting to convert the Doppler shift into actual blood flow, this is not possible since the precise angle of the crystal to the vessel wall is unknown and differs for each animal. However, because the change in the Doppler shift is both directly proportional to and linear to the change in actual blood flow, the magnitude of change in the Doppler shift is similar to that of actual flow. Importantly, the baseline flow velocity is stable with a narrow prediction interval. Small alterations in blood flow, which might be missed with an alternative technique, can therefore be detected. Based on our analyses of the baseline, we can state that change from a 10 -min baseline of $4.5 \mathrm{kHz}$ by $0.215 \mathrm{kHz}$ $(4.8 \%)$ would represent a statistically significant deviation from baseline $(P<0.05)$. The Doppler signal may be recorded as a pulsatile waveform or as an electronically meaned Doppler shift (MVS). The velocity signal is a temporal mean, but in a vessel less than $1 \mathrm{~mm}$ in diameter, it is identical to the spatial mean. A $0.5 \mathrm{~V}$ signal is equal to $1 \mathrm{kHz}$. By adjusting the time gate (range), the site of maximal flow within the vessel can be identified. At the beginning of each experiment, the maximal Doppler shift (flow velocity) is obtained and the range setting left unaltered for the duration of the experiment. We have observed that the range (and therefore the distance from the crystal to the point of maximal velocity) and uterine artery flow velocity increase with advancing gestation. The former may result from a lengthening of the vessel arc over the crystal as the uterus grows. Therefore, the Doppler shift during longitudinal studies taking place over 2-3 weeks is recorded in $\mathrm{kHz}$ for convenience.

Our findings concerning the effect of the three vasoactive agents confirm previous investigations (Ring, Krames, Shnider, Wallis \& Levinson, 1977; Tabsh et al., 1981) with sheep and extend them to another species.

Uterine artery flow velocity increased progressively during the gestational interval studied despite the frequent experiments. Heart rate was not recorded during these investigations, so we cannot separate out the effects of rate versus stroke volume. However, a previous report indicated that the increase in cardiac output during pregnancy in the guinea-pig is secondary to an increase in stroke volume (Morton et al., 1984). We noted that the extent to which the flow velocity increased seemed proportional to the number of young. The largest increases occurred in the animals with 4 and 5 young, and the smallest in the animal with 1 fetus. We have not yet explored the relationship 
between the percentage increase in flow velocity and total fetal weight or number of young (in animals which have been instrumented but not otherwise experimented upon). In addition, we found no evidence that manipulation and probe attachment to the uterine artery results in fetal growth retardation. There was a dramatic increase in flow velocity as the animal recovered from ketamine:xylazine general anaesthesia, suggesting that at least one of the agents reduces uterine artery flow velocity. Each of these observations supports earlier investigations using different techniques and/or models (Peeters, Grutters \& Martin, 1980; Myers et al., 1982; Meschia, 1983).

One possible source of error with the Doppler technique could result from vasoconstriction at the site of velocity measurement. It can be argued that, in an isolated resistance system, the reduction in the vessel diameter with maintenance of volume flow would necessitate an increase in flow velocity. It is, however, unlikely that the volume of flow will be completely maintained in vivo should there be a generalized increase in vascular resistance. To address this issue in part, we examined the effect of three previously studied vasoactive substances with markedly different effects on the uterine vasculature. The effect of hydralazine, angiotensin II and noradrenaline on MVS, MAP and resistance were similar both in direction and magnitude to those previously reported for the pregnant ewe (Ring et al., 1977; Tabsh et al., 1981). It therefore appears that the direction of change registered by Doppler flow velocity is reliable. It is possible that the magnitude of the flow volume decrease is underestimated by the reduction in flow velocity. However, Haywood et al. (1981) documented a high correlation between $\mathrm{kHz}$ and flow measured by electromagnetic flow probes despite the use of vasopressors, and Van Orden et al. (1984) have found a high correlation between $\mathrm{kHz}$ and microsphere-derived flow measurements after oestrogen administration. While this question must be further addressed in the future, it would appear that this technique provides for the first time a means to monitor, chronically and continuously, alterations of uterine artery blood flow in the pregnant guinea-pig.

The possible applications of this technique are numerous. It permits multiple experiments on one animal while providing immediate feedback and design modification if necessary. Most studies of uterine artery blood flow previously performed on larger animals can now be performed on the guinea-pig. Placement of a femoral artery catheter permits the simultaneous measurement of organ flow using radiolabelled microspheres. The placement of multiple probes will permit identification of regional differences in drug response (Tabsh et al., 1981).

Aided by Basil O'Connor Starter Research Grant No. 5-482 from the March of Dimes Birth Defects Foundation.

\section{References}

Challis, J.R.G., Heap, R.B. \& Illingworth, D.V. (1971)

Concentrations of oestrogen and progesterone in the plasma of nonpregnant, pregnant and lactating guinea pigs. J. Endocr. 51, 333-345.

Draper, R.L. (1920) The prenatal growth of the guinea pig. Anat. Rec. 18, 369-381.

Enders, A.C. (1965) A comparative study of the fine structure of the trophoblast in several hemochorial placentas. Am. J. Anat. 116, $29-67$.

Hartley, C.J. \& Cole, J.S. (1974) An ultrasound pulsed Doppler system for measuring blood flow in small vessels. J. appl. Physiol. 37, 626-629.

Haywood, J.R., Shaffer, R.A., Fastenow, C., Fink, G.D. \& Brody, M.J. (1981) Regional blood flow measurement in the conscious rat with pulsed Doppler flow meter. Am. J. Physiol. 241 (Heart Circ. Physiol. 10), $\mathrm{H} 273-\mathrm{H} 278$.
Hosenpud, J.D., Hart, M.V., Morton, M.J., Hohimer, A.R. \& Resko, J.A. (1983) Progesterone-induced hyperventilation in the guinea pig. Respiration Physiology 52, 259-264.

Martensson, L., Sjoquist, P.B., Bjellin, L. \& Carter, A.M. (1979) Myoendothelial and placental blood flow responses to ritodrine infusion in the guinea pig. $\mathrm{Am}$. J. Obstet. Gynecol. 135, 318-321.

Meschia, G. (1983) Circulation to female reproductive organs. Handbook Physiology; The Cardiovascular System, pp. 241-269. American Physiological Society, Washington, D.C.

Morton, M., Tsang, H., Hohimer, R., Ross, D., Thornburg, K., Faber, J. \& Metcalfe, J. (1984) Left ventricular size, output, and structure during guinea pig pregnancy. Am. J. Physiol. 246 (Regulatory Integrative Comp. Physiol. 15), R40-R48. 
Myers, S., Sparks, J.W., Makowski, E.L., Meschia, G. \& Battaglia, F.C. (1982) The relationship between placental blood flow and placental and fetal size in guinea pig. Am. J. Physiol. 243 (Heart Circ. Physiol. 12), H404-H409.

Peeters, L.L.H., Grutters, G. \& Martin, C.B. (1980) Distribution of cardiac output in the unstressed pregnant guinea pig. Am. J. Obstet. Gynecol. 138, 1177-1184.

Ring, G., Krames, E., Shnider, S.M., Wallis, K.L. \& Levinson, G. (1977) Comparison of nitroprusside and hydralazine in hypertensive pregnant ewes. Obstet. Gynecol. 50, 598-602.
Tabsh, K., Nuwayhid, B., Erkkola, R., Zugaib, S., Leib, E., Ushioda, E. \& Brinkman, C.R., III (1981) Hemodynamic responses of the pelvic vascular bed in pregnant sheep. Biol. Neonate 39, 52-60.

Van Orden, D.E., Farley, D.B., Fastenow, C. \& Brody, M.J. (1984) A technique for monitoring blood changes with miniaturized Doppler flow probes. Am. J. Physiol. 247 (Heart Circ. Physiol. 16), H1005-H1009.

Woodcock, J.P. (1975) Theory and Practice of Blood Flow Measurement. Butterworth, London.

Received 24 September 1985 